\title{
Stress Doppler echocardiography for early detection of systemic sclerosis-associated pulmonary arterial hypertension
}

Christian Nagel ${ }^{1,2}$, Philipp Henn', Nicola Ehlken', Antonello D’Andrea ${ }^{3}$, Norbert Blank $^{4}$, Eduardo Bossone ${ }^{5}$, Anke Böttger ${ }^{6}$, Christoph Fiehn ${ }^{7}$, Christine Fischer ${ }^{8}$, Hanns-Martin Lorenz ${ }^{4}$, Frank Stöckl ${ }^{9}$, Ekkehard Grünig ${ }^{1 *}$ and Benjamin Egenlauf ${ }^{1}$

\begin{abstract}
Introduction: In patients with systemic sclerosis (SSc), associated pulmonary arterial hypertension (SSc-APAH) is the leading cause of death. The objective of this prospective screening study was to analyse sensitivity and specificity of stress Doppler echocardiography (SDE) in detecting pulmonary hypertension (PH).

Methods: Pulmonary artery pressures and further parameters of $\mathrm{PH}$ were assessed by echocardiography and right heart catheterisation (RHC) at rest and during exercise in patients with SSc. Investigators of RHC were blinded to the results of non-invasive measurements.

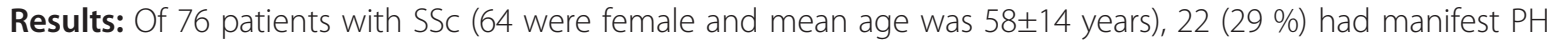
confirmed by RHC: four had concomitant left heart diseases, three had lung diseases, and 15 had SSc-APAH. Echocardiography at rest missed PH diagnosis in five of 22 patients with PH when a cutoff value for systolic pulmonary arterial pressure (PASP) was more than $40 \mathrm{~mm} \mathrm{Hg}$ at rest. The sensitivity of echocardiography at rest was $72.7 \%$ (95\% confidence interval (Cl) $0.52-0.88$ ), and specificity was $88.2 \%$ (95\% Cl 0.78-0.95). When a cutoff value for PASP was more than $45 \mathrm{~mm} \mathrm{Hg}$ during low-dose exercise, SDE missed PH diagnosis in one of the 22 patients with PH and improved sensitivity to $95.2 \%$ (95\% Cl $0.81-1.0)$ but reduced specificity to $84.9 \%$ (95\% Cl 0.74-0.93). Reduction of specificity was partly due to concomitant left heart disease.
\end{abstract}

Conclusions: The results of this prospective cross-sectional study using RHC as gold standard in all patients showed that SDE markedly improved sensitivity in detecting manifest PH to $95.2 \%$ compared with $72.7 \%$ using echocardiography at rest only. Thus, for PH screening in patients with SSc, echocardiography should be performed at rest and during exercise.

Trial registration: ClinicalTrials.gov NCT01387035. Registered 29 June 2011.

\section{Introduction}

Pulmonary hypertension $(\mathrm{PH})$ is a common complication of systemic sclerosis (SSc) which can occur at any stage of the disease and has been observed in 15-27\% of patients [1,2]. In most cases, $\mathrm{PH}$ is due to pulmonary arterial hypertension (PAH) which is associated with SSc (SSc-APAH). Three-year survival for patients with untreated SSc-APAH has been estimated to be $56 \%$

\footnotetext{
* Correspondence: ekkehard.gruenig@med.uni-heidelberg.de

${ }^{1}$ Centre for Pulmonary Hypertension Thoraxclinic, University Hospital

Heidelberg, Amalienstr. 5, 69126 Heidelberg, Germany

Full list of author information is available at the end of the article
}

compared with $91 \%$ in those patients without PAH [3]. According to the french itinerAir study, at PAH diagnosis, more than $80 \%$ of patients with SSc are in World Health Organization (WHO) functional class (FC) II-IV [4]. Today, $10 \mathrm{PAH}$-targeted drugs are available for these patients [5]. Therefore, an early diagnosis of PH/APAH is essential in patients with SSc.

Echocardiography at rest is the most important noninvasive method for the detection of $\mathrm{PH}$ and has been recommended for screening of patients at risk in several guidelines [6-8]. The reliability of tricuspid regurgitation velocity (TRV) cutoff values, with RHC as a reference, 
has previously been assessed in patients with SSc $[9,10]$. A TRV of at least $3.4 \mathrm{~m} / \mathrm{s}$ with an assumed right atrial (RA) pressure of $5 \mathrm{~mm} \mathrm{Hg}$ (corresponding to a systolic pulmonary arterial pressure (PASP) of $50 \mathrm{~mm} \mathrm{Hg}$ ) has been recommended as a cutoff value for performing $\mathrm{RHC}$ to diagnose or exclude $\mathrm{PH}$ in the European Society of Cardiology/European Respiratory Society (ESC/ERS) guidelines [6]. In a multicenter study aiming at the development of a screening algorithm in SSc patients (DETECT study), transthoracic Doppler echocardiography (TDE) at rest using these cutoff values alone was not reliable to detect early forms of SSc-APAH [11]. In this study, RHC was performed in each patient with SSc. The study showed that, of 84 patients with manifest SSc-APAH, only $30 \%$ had a TRV of more than $3.4 \mathrm{~m} / \mathrm{s}$ at rest and $57 \%$ of more than $2.8 \mathrm{~m} / \mathrm{s}$. Thirty-six percent of patients would have been overlooked if only TDE had been used [11]. When using the screening algorithm of the DETECT study, including TDE, diffusing capacity of the lung for carbon monoxide (DLCO), electrocardiogram and further laboratory parameters, only $4 \%$ of patients were missed [11]. Previous studies showed that patients with SSc and increased pulmonary arterial pressure response to exercise were impaired in their physical exercise capacity [12]. Furthermore, they were more prone to develop a manifest $\mathrm{PH}$ within 1-3 years [13] and had a worse prognosis [14].

Thus, assessing exercise haemodynamics obtained by RHC and by non-invasive stress Doppler echocardiography (SDE) may identify abnormal pulmonary circulation and may help to identify patients with PH/SSc-APAH at an early stage [15]. However, the role of SDE for PH screening is unclear because of the lack of prospective confirmatory data $[6,7]$. Therefore, the objective of this prospective study was to analyse whether SDE improves sensitivity and specificity of detecting $\mathrm{PH}$ in comparison with echocardiography at rest. To confirm diagnosis, RHC at rest and during exercise was performed in all patients.

\section{Methods}

\section{Study population and design}

The study was designed as a prospective cross-sectional study in which SSc patients without known $\mathrm{PH}$ have been systematically screened by using echocardiography at rest, SDE, and RHC [16]. The investigators who performed echocardiography and SDE were blinded to the results of RHC. To minimise bias, RHC as the confirmatory diagnostic test was performed in each patient.

Patients who had diffuse cutaneous systemic sclerosis (dcSSc) and limited cutaneous systemic sclerosis (lcSSc) (CREST syndrome) and were at least 18 years old were included. Diagnosis of SSc was confirmed by experienced rheumatologists (NB, AB, CFie, H-ML, and FS) according to the standard criteria of the American College of Rheumatology [17]. Exclusion criteria were the following: manifest PH confirmed by RHC prior to enrolment, receiving $\mathrm{PH}$ therapy, forced vital capacity (FVC) of less than $40 \%$ of predicted, renal insufficiency, systemic arterial hypertension with pressure values of more than $160 / 90 \mathrm{~mm} \mathrm{Hg}$ at rest or more than $220 / 120 \mathrm{~mm} \mathrm{Hg}$ during exercise despite optimised medical treatment, previous evidence of clinically relevant left heart disease, or pregnancy.

All patients underwent a detailed clinical work-up, including medical history, physical examination, electrocardiogram, two-dimensional echocardiography at rest and during exercise, lung function test, arterial blood gases, chest $\mathrm{x}$-ray, 6-minute walking distance (6MWD) under standardised conditions [18], laboratory testing including NT-proBNP (N-terminal of the prohormone brain natriuretic peptide) levels, and RHC. Twelve-lead electrocardiogram was performed in all patients (Hellige EK 512 P, Hellige, Freiburg, Germany). Ventilation/perfusion scintigraphy, (Philips Axis, Philips, Hamburg, Germany), computed tomography (Siemens Somatom, Definition AF \& Emotion, Siemens, Berlin and Munich, Germany). Scan of the lungs, and left heart catheterisation were performed in all patients with suspected chronic thromboembolic PH, left heart, or respiratory diseases and when clinically indicated. Manifest PH/APAH has been diagnosed according to the current ERS/ESC guidelines [6, 7].

\section{Transthoracic Doppler echocardiography at rest}

A complete echocardiographic examination was done prior to exercise. Two-dimensional and colour-flow-guided continuous-wave Doppler echocardiographic recordings at rest and during exercise were obtained by experienced cardiac sonographers (EG and $\mathrm{CN}$ ) using 3.6-4 $\mathrm{MHz}$ Duplex probes and conventional equipment (Vivid 7, GE Healthcare, Milwaukee, WI, USA) at rest and during exercise testing as described previously [16]. PASP was estimated from peak tricuspid regurgitation jet velocities according to the equation: PASP $=4(\mathrm{~V})^{2}+$ RA pressure, where $\mathrm{V}$ is the peak velocity (in metres per second) of TRV [19]. For all calculations, the mean value of at least three TRV measurements was used. RA pressure was estimated from characteristics of the inferior vena cava [20]. If it was less than $20 \mathrm{~mm}$ in diameter and decreased during inspiration, we added $5 \mathrm{~mm} \mathrm{Hg}$; if it was at least $20 \mathrm{~mm}$, we added $10 \mathrm{~mm} \mathrm{Hg}$.

\section{Stress Doppler echocardiography}

Patients were examined on a variable load $45^{\circ}$ cycle ergometer (model 8420; KHL Corp., Kirkland, WA, USA) as described previously [16]. Workload was started at 25 Watts and increased by 25 Watts every 2 min to an exercise capacity or symptom-limited maximum. TRV, heart rate, oxygen saturation, and systemic blood pressure were analysed at each stage. Echocardiographic assessment was stored in DICOM (Digital Imaging and 
Communications in Medicine) format for further offline analysis.

\section{Right heart catheter}

Patients were examined on a variable load supine bicycle ergometer (model 8420; KHL Corp.) by an experienced investigator $(\mathrm{BE})$ who was blinded to the results of echocardiography and SDE. The examination at rest was performed as previously described [16] in a supine position by using the transjugular access with an $8 \mathrm{~F}$ introducer set (MXI100, MEDEX, Smiths Group PLC, London, UK). Catheterisation was done by triple-lumen 7 F-Swan-Ganz thermodilution catheters by Edwards Lifesciences (REF:131 F7, Edwards Lifesciences LLC, Irvine, CA, USA). Pressures were continuously recorded and averaged over several respiratory cycles during spontaneous breathing, both at rest and during exercise. Cardiac output (CO) was measured by thermodilution at least in triplicate with a variation of less than $10 \%$ between the measured values. The zero reference point for pressure recordings was set at $1 / 3$ of the thoracic diameter below the anterior thorax surface [21]. After the hemodynamic measurement at rest, the supine position was changed to a $45^{\circ}$ position. The zero reference point was calibrated to the pulmonary arterial wedge pressure (PAWP). After careful calibration, the hemodynamic parameters at rest were measured again and the exercise test was started with a workload of 25 Watts. Workload was incrementally increased by 25 Watts every 2 min to an exercise capacity or symptom-limited maximum. All examinations and measurements were performed by the same experienced team. There were no complications.

\section{Cutoff values of systolic pulmonary arterial pressures at rest and during mild to moderate exercise}

In this study, we used PASPs of more than $40 \mathrm{~mm} \mathrm{Hg}$ at rest and of more than $45 \mathrm{~mm} \mathrm{Hg}$ during low-dose exercise (25-50 Watts over 2 minutes) as cutoff values for the non-invasive detection of manifest $\mathrm{PH}$. These thresholds are based on previous publications, stating that healthy subjects do not exceed these values at rest [16] or during low-dose exercise [22] defined as CO below 10 1/min. Furthermore, with the Chemla formula (mean pulmonary arterial pressure $\left.(\mathrm{mPAP})=0.61^{*} \mathrm{PASP}+2 \mathrm{~mm} \mathrm{Hg}\right)[23]$ or the Syyed formula (mPAP $=0.65^{*}$ PASP $+0.55 \mathrm{~mm} \mathrm{Hg}$ ) [24], which both revealed a high accuracy and precision [25], mPAP of $25 \mathrm{~mm} \mathrm{Hg}$ at rest is equal to a PASP of 38 $\mathrm{mm} \mathrm{Hg}$, and mPAP of $30 \mathrm{~mm} \mathrm{Hg}$ during exercise would reflect a PASP of $45.9 \mathrm{~mm} \mathrm{Hg}$. These PASP cutoff values are also within the recommended values mentioned in the ERS/ESC guidelines for PH [16].

\section{Ethics statement}

This study was conducted in accordance with Good Clinical Practice and the current version of the revised
Declaration of Helsinki (World Medical Association Declaration of Helsinki). The ethics committee of the University of Heidelberg approved the study (Internal Ethics-Nr. S-360/2009). Written informed consent was obtained from each patient prior to enrolment.

\section{Statistical methods}

Baseline was defined as the day when the patient underwent echocardiography at rest and SDE. PH and non$\mathrm{PH}$ groups were described by using summary statistics: sample size, mean, and standard deviation for quantitative data and frequencies (counts and percentages) for qualitative and categorical data. Differences between groups were analysed with an unpaired two-sided Student's $t$ test. All tests were two-sided, and $P$ values of less than 0.05 were considered statistically significant.

Sensitivity and specificity for echocardiography at rest and during exercise using cutoff values for PASP of 40 $\mathrm{mm} \mathrm{Hg}$ at rest and $45 \mathrm{~mm} \mathrm{Hg}$ during exercise were calculated separately and in combination of the two methods compared with RHC as gold standard. We report $95 \%$ confidence intervals (CIs) for sensitivity and specificity estimates. For the combination of echocardiography at rest and during exercise, a patient was classified as having PH when being above the threshold for at least one method. For further analysis of suitability of the thresholds, receiver operating characteristic (ROC) and area under the curve estimates with $95 \%$ confidence intervals are shown. We also performed multiple regression analysis with stepwise forward selection of parameters for predicting MPAP at rest as metric variable and also for binary classification of PH (mPAP $\geq 25 \mathrm{~mm} \mathrm{Hg}$ versus $\mathrm{mPAP}<25 \mathrm{~mm} \mathrm{Hg}$ ). Parameters included in multiple regression were age, gender, DLCO (percentage), FVC (percentage), systolic pulmonary arterial pressure at rest, at 25 Watts, RA area, right ventricular (RV) area, and tricuspid annular plane systolic excursion (TAPSE). All analyses were carried out with IBM SPSS 20 (SPSS Statistics version 20, IBM Corporation, Armonk, NY, USA).

\section{Results}

\section{Study population}

During the study, 81 patients with SSc were screened, and five were excluded for the following reasons: the diagnosis of SSc was not confirmed in three patients by an experienced rheumatologist, and two patients were not willing to perform an RHC. Thus, the final study group consisted of 76 consecutive patients with SSc: $59 \%$ $(n=45)$ of these patients were diagnosed with dcSSc, and $41 \%(n=31)$ with lcSSc. The mean age was $58 \pm 14$ years, and there were $12(16 \%)$ males and $64(84 \%)$ females (Table 1). The youngest patient was 28 years old; the oldest was 82 years old. The duration of SSc at the time of 
Table 1 Characteristics of scleroderma patients

\begin{tabular}{llll}
\hline Number of included patients & \multicolumn{3}{l}{76} \\
\hline Gender, female/male & 64 & $/$ & 12 \\
Age, years & 57.9 & \pm & 14.4 \\
Duration of systemic sclerosis, years & 12.0 & \pm & 11.3 \\
Body weight, kg & 68.8 & \pm & 14.0 \\
Body height, cm & 165.5 & \pm & 8.1 \\
Body surface area, m ${ }^{2}$ & 1.8 & \pm & 0.2 \\
WHO functional class & & & \\
0-I & 17 & & $22 \%$ \\
II & 31 & & $41 \%$ \\
III & 27 & & $36 \%$ \\
6-minute-walking-distance, m & 435 & \pm & 94.4 \\
Borg Dyspnoea Scale (6-20) & 13.8 & \pm & 2.4 \\
Haemodynamics by right heart catheter & & & \\
mPAP, mm Hg & 20.1 & \pm & 9.6 \\
PVR, dynes ${ }^{*}$ sec per cm ${ }^{5}$ & 181.4 & \pm & 151.9 \\
PAWP, mm Hg & 8.8 & \pm & 4.9 \\
Cardiac output, l/min & 5.4 & \pm & 1.2 \\
Cardiac index, I/min per m ${ }^{2}$ & 3.0 & \pm & 0.6 \\
\hline Vaues are given as number man & &
\end{tabular}

Values are given as number, mean \pm standard deviation, or number and percentage

WHO World Health Organization, MPAP mean pulmonary arterial pressure, $P V R$ pulmonary vascular resistance, $P A W P$ pulmonary arterial wedge pressure

the first visit was $12.0 \pm 11.3$ years, and the minimum duration was 16 months. None of these patients had a history of $\mathrm{RHC}$ or targeted oral medication for PH or digital ulcerations. Clinical findings at baseline are shown in Table 1.

At baseline, 17 of the 76 patients (22\%) presented with no signs of dyspnoea in everyday life and during exercise and therefore were categorized as WHO FC 0-I. Thirty patients (41\%) were categorized as WHO FC II, and 27 patients (36\%) as WHO FC III. WHO FC was not documented in one patient.

\section{Diagnosis of manifest pulmonary hypertension by right heart catheterisation}

Twenty-two (29\%) of 76 patients with SSc had an elevated mPAP of at least $25 \mathrm{~mm} \mathrm{Hg}$ and therefore a manifest PH (Fig. 1). Four of these 22 patients with $\mathrm{PH}$ showed an elevated PAWP of more than $15 \mathrm{~mm} \mathrm{Hg}$. Further diagnostic work-up by left heart catheter revealed a coronary heart disease or left heart failure with preserved ejection fraction (HFpEF) (or both) in two patients. Signs of significant pulmonary fibrosis in a CT scan and an FVC of less than $70 \%$ were found in four patients with $\mathrm{PH}$. Three patients were classified as having $\mathrm{PH}$-interstitial lung disease. One patient presented with a PAWP of more than $15 \mathrm{~mm} \mathrm{Hg}$ and was classified as having $\mathrm{PH}$ with left heart disease after further diagnostic work-up, including left heart catheterisation.

In 21 patients (28\%), mPAPs were between 21 and 24 $\mathrm{mm} \mathrm{Hg}$ at rest (borderline) or more than $30 \mathrm{~mm} \mathrm{Hg}$ during exercise or both. In two patients out of this group, coronary heart disease or HFPEF or both were diagnosed by left heart catheterisation (Fig. 1). Thirty-three patients with SSc (43\%) presented with normal mPAP at rest and during exercise (Fig. 1).

Patients with newly diagnosed manifest $\mathrm{PH}$ revealed a mean mPAP of $33 \pm 8 \mathrm{~mm} \mathrm{Hg}$ and a mean pulmonary vascular resistance of $339 \pm 199$ dynes*s per $\mathrm{cm}^{5}$, indicating an early diagnosis reached by the screening procedure of this study (Table 2).

\section{Comparison between patients without and with pulmonary hypertension}

Patients in the PH group were significantly older with a later SSc diagnosis and had a higher Modified Rodnan Skin Score and therefore a more severe skin involvement (Table 2). Patients with $\mathrm{PH}$ had been categorized in higher WHO FC and revealed significantly lower 6MWD and a higher Borg Index and NT-proBNP levels than patients without $\mathrm{PH}$. Patients with $\mathrm{PH}$ had a significantly larger RA and RV area, larger thickness of the free RV wall, and a lower tricuspid annular plane systolic excursion than non-PH patients (Table 2). There were no significant differences between the two groups concerning $\mathrm{CO}$ at rest. During maximum exercise, the $\mathrm{PH}$ group showed a significantly lower $\mathrm{CO}$ than the non- $\mathrm{PH}$ group and had a worse RV contractile reserve (Table 2).

\section{Sensitivity and specificity of echocardiography at rest versus stress Doppler echocardiography during exercise} Echocardiography at rest revealed a sensitivity in diagnosing manifest $\mathrm{PH}$ of $72.7 \%$ (95\% CI 52-88 \%) and a specificity of $88.2 \%$ (95 \% CI 78-95\%) when a cutoff PASP value of $40 \mathrm{~mm} \mathrm{Hg}$ was used (Fig. 2a).

SDE with a workload of 25 Watts was possible in 74 (97\%) of the 76 patients. One patient refused exercise testing; another patient had to miss the exam because of a foot injury. A further eight patients had to stop exercise testing before cardiopulmonary limitation because of orthopaedic problems: six patients (7.9\%) had coxarthrosis or knee arthrosis or both, and two patients $(2.6 \%)$ had knee replacement implants. However, these patients completed the workload of 25 Watts and could be included in the exercise echocardiography analysis.

SDE had a sensitivity in diagnosing manifest $\mathrm{PH}$ by measuring the PASP during low-dose exercise (25 Watt) of $95.2 \%$ (95\% CI 81-100\%) and a specificity of $84.9 \%$ (95\% CI 74-93\%) when a cutoff value of more than 45 mm Hg was used (Fig. 2b). 


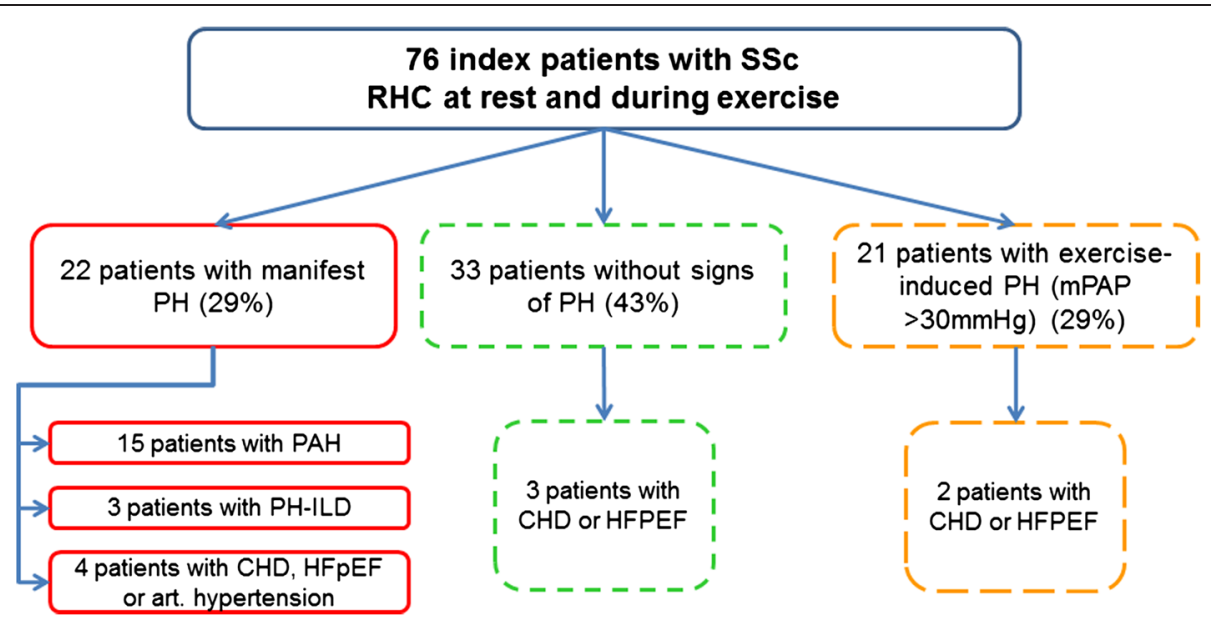

Fig. 1 Results of the screening of 76 patients with systemic sclerosis (SSC) by right heart catheterisation (RHC). This figure shows that within the screening assessment $29 \%$ of the 76 patients were newly diagnosed with a manifest pulmonary hypertension (PH) and $43 \%$ had no signs of PH. CHD coronary heart disease, HFpEF heart failure with preserved ejection fraction, MPAP mean pulmonary arterial pressure, PH-ILD pulmonary hypertension-interstitial lung disease

In multiple regression analysis, at 25 Watts was the most important independent parameter to determine mPAP $(\mathrm{R}=0.856, P>0.001)$. For binary classification of diagnosis of $\mathrm{PH}$, at 25 Watts was the only independent predictor $(\mathrm{R}=0.779, P<0.001)$.

The two thresholds, $40 \mathrm{~mm} \mathrm{Hg}$ PASP at rest and 45 $\mathrm{mm} \mathrm{Hg}$ PASP during exercise at 25 Watts, were analysed by ROC analysis for their suitability (Fig. 3). The cutoff value for echocardiography during exercise at 45 $\mathrm{mm} \mathrm{Hg}$ revealed the highest combination of sensitivity and specificity. For the examination at rest, a lower cutoff value would have led to an increase of sensitivity but a crucial decrease of specificity.

It was even possible to increase the sensitivity of diagnosing a manifest $\mathrm{PH}$ by combination of TDE at rest and during exercise, as shown in Fig. 4 (the squares symbolize those patients with an invasively diagnosed manifest PH). With cutoff values of $40 \mathrm{~mm} \mathrm{Hg}$ for PASP at rest and of $45 \mathrm{~mm} \mathrm{Hg}$ at a workload of 25 Watts, 21 out of 22 patients with manifest $\mathrm{PH}$ have been identified. A comparison of different screening algorithms including the combination of PASP at rest and at 25 Watts is given in Table 3.

One patient who would have been missed by the combination of TDE at rest and SDE presented with only a mild PH with an mPAP of just $26 \mathrm{~mm} \mathrm{Hg}$ and PASP of less than $45 \mathrm{~mm} \mathrm{Hg}$ at rest and during exercise.

Six further patients had PASPs at 25 Watts of more than $45 \mathrm{~mm} \mathrm{Hg}$ with an mPAP of less than $25 \mathrm{~mm} \mathrm{Hg}$. These patients were "false-positive" because of elevated PAWP during exercise. The further diagnostic work-up showed that two of them had coronary heart disease and that four had an HFpEF and therefore a post capillary exercise-induced $\mathrm{PH}$ and no $\mathrm{PAH}$.

\section{Safety}

In the examination by SDE in all patients, TRV could be successfully measured at rest and during exercise because of the presence of tricuspid regurgitation in the enlarged right hearts. SDE and RHC during low workloads were safe and could be performed without complications in all patients.

\section{Discussion}

This is the first prospective study evaluating sensitivity and specificity of echocardiography at rest and during low-dose exercise ( 25 Watts, $\mathrm{CO}<10 \mathrm{l} / \mathrm{min}$ ) compared with RHC in patients with SSc. With cutoff values of PASP of $40 \mathrm{~mm} \mathrm{Hg}$ at rest and $45 \mathrm{~mm} \mathrm{Hg}$ during lowdose exercise, SDE markedly improved the sensitivity to identify patients with manifest $\mathrm{PH}$ (diagnosed by RHC) from $72.7 \%$ to $95.2 \%$ compared with echocardiography at rest only. Specificity of PAH diagnosis by SDE was $84.9 \%$ and was reduced mainly because of concomitant cardiovascular diseases. SDE detected even patients with only mild manifest $\mathrm{PH} / \mathrm{PAH}-\mathrm{SSc}$ at an early stage (mPAP of 25-30 mm Hg), which was often overlook by echocardiography at rest only. Thus, SDE may be a useful noninvasive technique to identify SSc patients with $\mathrm{PH} / \mathrm{PAH}$ at an early stage.

Pulmonary hypertension screening in systemic sclerosis patients using transthoracic Doppler echocardiography at rest

Echocardiography at rest has been used for PH screening in SSc patients for more than 20 years [26]. However, in contrast to our study, all previous studies except the DETECT study did not systematically use RHC in all patients. Denton et al. [27] found a higher sensitivity of $90 \%$ and a 
Table 2 Comparison between no pulmonary hypertension and manifest pulmonary hypertension group

\begin{tabular}{|c|c|c|c|c|c|c|}
\hline \multirow[t]{3}{*}{ Diagnosis } & & \multicolumn{2}{|l|}{$\mathrm{No} P H$} & \multicolumn{2}{|l|}{ Manifest PH } & \multirow[b]{3}{*}{$P$ value } \\
\hline & & $n=54$ & & $n=22$ & & \\
\hline & & Mean & SD & Mean & SD & \\
\hline \multirow[t]{9}{*}{ Patient characteristics } & Age, years & 54.0 & 14.4 & 67.6 & 8.8 & $<0.001$ \\
\hline & Height, $\mathrm{cm}$ & 167.3 & 7.8 & 162.1 & 8.1 & 0.02 \\
\hline & Weight, kg & 70.0 & 16.0 & 66.0 & 10.5 & n.s. \\
\hline & Body surface area, $\mathrm{m}^{2}$ & 1.77 & 0.2 & 1.7 & 0.2 & n.s. \\
\hline & Duration of SSc, years & 10.7 & 9.9 & 15.6 & 14.4 & n.s. \\
\hline & Beginning of SSC, years & 44.5 & 15.0 & 52.4 & 16.0 & 0.04 \\
\hline & Modified Rodnan Skin Score & 13.3 & 8.5 & 18.4 & 11.4 & 0.04 \\
\hline & $6 \mathrm{MWD}, \mathrm{m}$ & 466 & 77 & 349 & 86 & $<0.001$ \\
\hline & Borg Dyspnoea 20 & 13 & 2 & 15 & 2 & 0.003 \\
\hline \multirow[t]{4}{*}{ WHO FC } & $0-1$ & \multicolumn{2}{|l|}{17 (31.5\%) } & \multicolumn{2}{|l|}{0} & \\
\hline & $\|$ & \multicolumn{2}{|l|}{$26(48.1 \%)$} & \multicolumn{2}{|l|}{$5(22.7 \%)$} & \\
\hline & III & \multicolumn{2}{|l|}{$10(18.5 \%)$} & \multicolumn{2}{|l|}{$17(77.3 \%)$} & \\
\hline & Unknown & \multicolumn{2}{|l|}{$1(1.9 \%)$} & \multicolumn{2}{|c|}{0} & \\
\hline Laboratory & NT-proBNP, pg/mL & 290 & 424 & 846 & 773.0 & 0.02 \\
\hline Blood gas analysis & Oxygen saturation, \% & 96.8 & 2.1 & 94.6 & 3.4 & 0.01 \\
\hline \multirow[t]{4}{*}{ Lung function } & Vital capacity, \% & 95.8 & 24.2 & 88.2 & 29.9 & n.s. \\
\hline & FEV1, \% & 108.0 & 93.7 & 83.7 & 26.9 & n.s. \\
\hline & Total lung capacity, \% & 95.5 & 21.4 & 83.8 & 23.2 & 0.042 \\
\hline & Residual volume, \% & 2.0 & 0.8 & 1.9 & 0.6 & n.s. \\
\hline Diffusion capacity & Diffusion capacity carbon monoxide, \% & 55.7 & 13.5 & 42.1 & 12.5 & $<0.001$ \\
\hline Echocardio- & $\mathrm{RV}$ thickness, mm & 6.5 & 1.2 & 7.6 & 1.4 & 0.01 \\
\hline \multirow[t]{6}{*}{ graphy } & TAPSE, mm & 24.0 & 3.5 & 20.6 & 4.0 & 0.001 \\
\hline & $\mathrm{RA}$ area, $\mathrm{cm}^{2}$ & 11.4 & 3.3 & 15.5 & 5.7 & $<0.001$ \\
\hline & $\mathrm{RV}$ area, $\mathrm{cm}^{2}$ & 14.6 & 3.7 & 17.7 & 4.2 & 0.003 \\
\hline & $\mathrm{TRV}, \mathrm{m} / \mathrm{s}$ & 2.3 & 0.4 & 3.4 & 0.6 & $<0.001$ \\
\hline & PASP, $\mathrm{mm} \mathrm{Hg}$ & 25.6 & 7.3 & 52.0 & 18.0 & $<0.001$ \\
\hline & PASP max (exercise), mm Hg & 49.9 & 12.7 & 83.9 & 18.9 & $<0.001$ \\
\hline Right heart & $\mathrm{RAP} / \mathrm{CVP}, \mathrm{mm} \mathrm{Hg}$ & 3.8 & 2.6 & 6.3 & 4.5 & 0.02 \\
\hline catheterisation & mPAP, $\mathrm{mm} \mathrm{Hg}$ & 14.8 & 3.4 & 32.6 & 7.5 & $<0.001$ \\
\hline \multirow[t]{4}{*}{ at rest } & PAWP, mm Hg & 7.2 & 3.2 & 12.4 & 6.0 & 0.001 \\
\hline & Cardiac output, $\mathrm{ml} / \mathrm{min}$ & 5.6 & 1.3 & 5.1 & 1.0 & n.s. \\
\hline & Cardiac index, $1 /$ min per $\mathrm{m}^{2}$ & 3.1 & 0.6 & 2.9 & 0.5 & n.s. \\
\hline & PVR, dynes* $/ \mathrm{cm}^{5}$ & 114 & 40 & 339 & 199 & $<0.001$ \\
\hline \multirow[t]{4}{*}{ During exercise } & mPAP max, mm Hg & 31 & 7 & 50 & 7 & $<0.001$ \\
\hline & PAWP max, mm Hg & 17 & 6 & 21 & 9 & n.s. \\
\hline & Cardiac output max, I/min & 11.5 & 3.4 & 8.3 & 2.9 & $<0.001$ \\
\hline & PVR max, dynes*s/ $\mathrm{cm}^{5}$ & 96 & 42 & 323 & 207 & $<0.001$ \\
\hline
\end{tabular}

PH pulmonary hypertension, MPAP mean pulmonary arterial pressure, SD standard deviation, SSc systemic sclerosis, 6MWD 6-minute walking distance, WHO FC World Health Organization functional class, NT-proBNP N-terminal of the prohormone brain natriuretic peptide, n.s. not significant, FEV1 forced expiratory volume in 1 second, RV right ventricle, TAPSE tricuspid annular plane systolic excursion, RA right atrium, TRV tricuspid regurgitation velocity, PASP systolic pulmonary arterial pressure, RAP right atrial pressure, CVP central venous pressure, PAWP pulmonary arterial wedge pressure, PVR pulmonary vascular resistance

$P$ values are based on two-sided, unpaired Student's $t$ tests and Mann-Whitney $U$ test for Borg Dyspnoea Scale score. For Borg Dyspnoea Scale score, median values equal means. Values are mean \pm SD. For the category of NT-proBNP, values were missing for 14 patients in the mPAP $<25 \mathrm{~mm} H \mathrm{H}$ and eight patients in the $\mathrm{mPAP} \geq 25 \mathrm{~mm} \mathrm{Hg}$ group. For the category of RV thickness, values were missing for seven patients for each group. For the categories of RA area, RV area, and TRV, values for one patient were missing in the mPAP $<25 \mathrm{~mm} \mathrm{Hg}$ group. For the category of PASP, values were missing for three patients in the mPAP $<25 \mathrm{~mm}$ $\mathrm{Hg}$ group. For the category of PASP max (exercise), values were missing for three patients in the mPAP $<25 \mathrm{~mm} \mathrm{Hg}$ group. For the categories of cardiac index, mPAP max, PWAP max, cardiac output max, and cardiac index max, values for one patient was missing for each group, respectively 
a) PASP at rest $[\mathrm{mmHg}]$

measured by echocardiography at rest

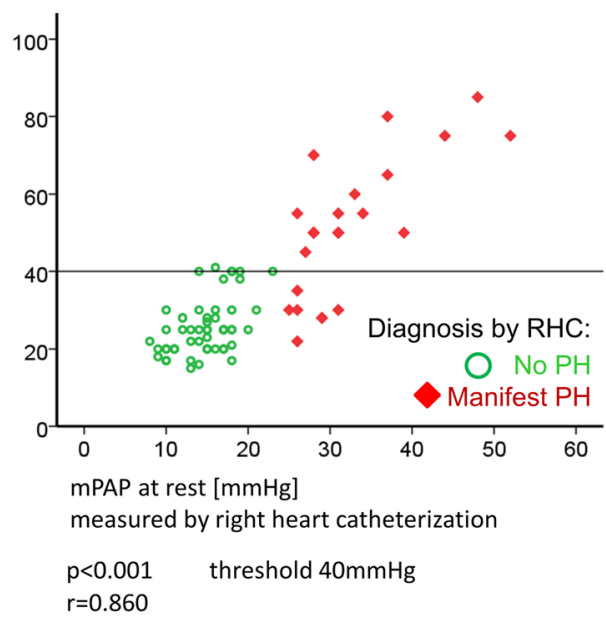

Sensitivity $72.7 \%[95 \% \mathrm{Cl} 52-88]$

Specificity $88.2 \%$ [95\% Cl 78-95] b) PASP at 25 Watt $[\mathrm{mmHg}]$

measured by Stress-Doppler echocardiography

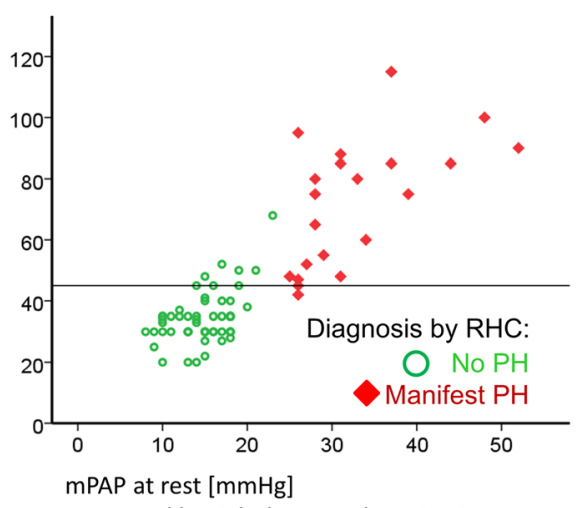

measured by right heart catheterization

$p<0.001 \quad$ threshold $45 \mathrm{mmHg}$
$\mathrm{r}=0.860$

Sensitivity $95.2 \%[95 \% \mathrm{Cl} 81-100]$ Specificity $84.9 \%[95 \% \mathrm{Cl} 74-93]$

Fig. 2 a Correlation of systolic pulmonary arterial pressures (PASP) determined by echocardiography and mean pulmonary arterial pressure (mPAP) at rest. The $x$-axis shows the PASP values measured by echocardiography at rest, the $y$-axis the values measured by right heart catheterisation (RHC). The values of each patient are given in red, indicating that the assessment including RHC diagnosed a manifest pulmonary hypertension (PH) with an mPAP at rest of at least $25 \mathrm{~mm} \mathrm{Hg}$. The symbols in green are the values of systemic sclerosis patients with no manifest PH at rest. As cutoff value for the PASP, $40 \mathrm{~mm} \mathrm{Hg}$ at rest was used. The sensitivity was $72.7 \%$ (95\% confidence interval (Cl) 52-88 \%) and the specificity was $88.2 \%$ (95\% Cl $78-95$ $\%)$ in diagnosing a PH $(P<0.001)$. There was a positive correlation $(r=0.860)$ between PASP and mPAP. $\mathbf{b}$ Correlation of PASP at 25 Watts and mPAP at rest. The $x$-axis shows the PASP values measured by echocardiography during low-dose exercise at 25 Watts. The $y$-axis shows the values measured by RHC at rest. Sensitivity was $95.2 \%$ (95 \% Cl 81-100 \%) and specificity was $84.9 \%$ (95 \% Cl 74-93\%) in diagnosing a PH using a cutoff PASP value of $45 \mathrm{~mm} \mathrm{Hg}$ at 25 Watts $(P<0.001)$. Positive correlation $(r=0.860)$ between PASP at 25 Watts and mPAP

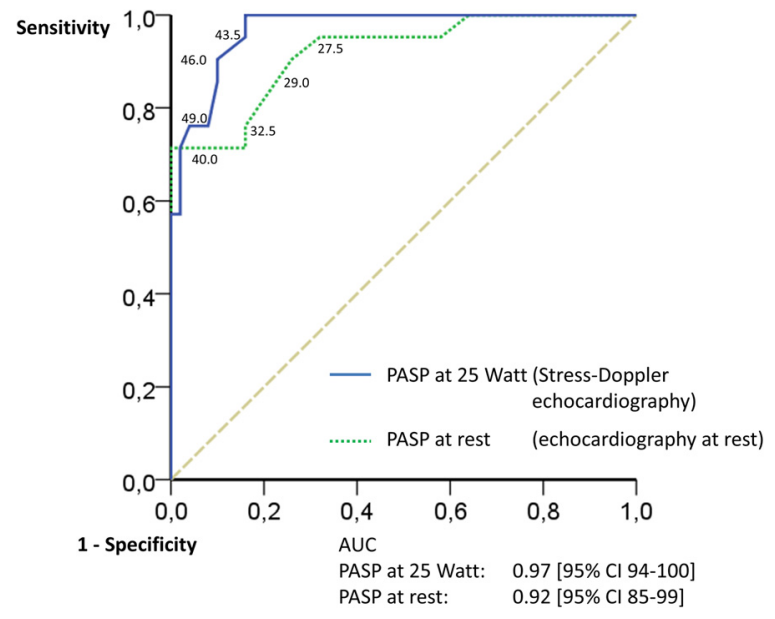

Fig. 3 Receiver operating characteristic (ROC) curves of sensitivity and specificity of systolic pulmonary arterial pressures (PASP) at rest and at 25 Watts. The threshold for detection of pulmonary hypertension was set at $40 \mathrm{~mm} \mathrm{Hg}$ for echocardiography at rest and at $45 \mathrm{~mm} \mathrm{Hg}$ for echocardiography during exercise. All possible thresholds were analysed by ROC analysis for their suitability. The cutoff value for echocardiography during exercise at $45 \mathrm{~mm} \mathrm{Hg}$ revealed the highest combination of sensitivity and specificity. For the examination at rest, a decrease of the cutoff value would have led to an increase of sensitivity but a crucial decrease of specificity. AUC area under the curve, $\mathrm{Cl}$ confidence interval specificity of $75 \%$ for echocardiography at rest and identified manifest SSc-APAH by RHC in $64 \%$ of patients. However, this was a highly pre-selected patient cohort. In our prospective study, patients have been consecutively included even when they had no symptoms. Mukerjee et al. [9] described sensitivity and specificity values according to different cutoff values of PASP at rest of at least 30 $\mathrm{mm} \mathrm{Hg}$, at least $35 \mathrm{~mm} \mathrm{Hg}$, at least $40 \mathrm{~mm} \mathrm{Hg}$, and at least $45 \mathrm{~mm} \mathrm{Hg}$ of $88 / 42 \%, 75 / 66 \%, 58 / 87 \%$, and $47 / 97$ $\%$, respectively. Their conclusion was that TDE at rest is not a useful screening tool for early SSc-APAH but may provide a moderate specificity in advanced PAH. Hsu et al. detected a sensitivity of TDE diagnosing $\mathrm{PH}$ in a high-risk cohort of patients with symptomatic SSc (49\% were diagnosed with $\mathrm{PH}$ ) of $58 \%$ using a cutoff level of $47 \mathrm{~mm} \mathrm{Hg}$ [28]. These previous findings are in contrast to those of the DETECT study, in which RHC was performed in each patient with SSc. Of the 85 patients with manifest SSc-APAH, only $29.8 \%$ had a TRV of at least $3.4 \mathrm{~m} / \mathrm{s}$ at rest corresponding to a cutoff PASP value of $50 \mathrm{~mm} \mathrm{Hg}$ [11]. Thirty-six percent of patients with manifest PH would have been overlooked using TDE at rest only [11] using a cutoff value of $2.8 \mathrm{~m} / \mathrm{s}$ corresponding to $40 \mathrm{~mm} \mathrm{Hg}$ at rest. The results of the DETECT study have been confirmed in a retrospective 
PASP at rest $[\mathrm{mmHg}]$

measured by echocardiography at rest

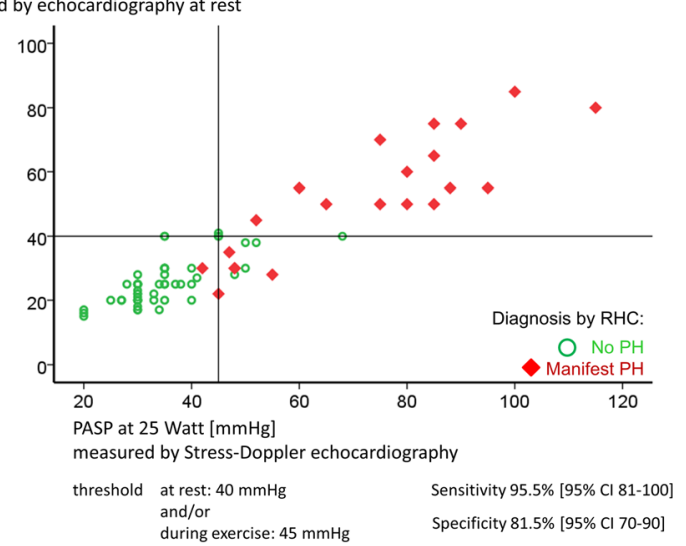

Fig. 4 Correlation of systolic pulmonary arterial pressure (PASP) at 25 Watts and PASP at rest. Cutoff values are $45 \mathrm{~mm} \mathrm{Hg}$ for PASP at 25 Watts and $40 \mathrm{~mm} \mathrm{Hg}$ PASP at rest. Circles represent patients without pulmonary hypertension $(\mathrm{PH})$ verified by right heart catheterisation ( $\mathrm{RHC}$ ); squares are patients with manifest associated pulmonary arterial hypertension according to $\mathrm{RHC}$ as gold standard. PASP at rest with a cutoff value of $40 \mathrm{~mm} \mathrm{Hg}$ would have missed five manifest PH patients; PASP at 25 watts with a cutoff value of 45 $\mathrm{mm} \mathrm{Hg}$ would have missed only one patient with a slightly lower specificity. Cl confidence interval

analysis showing that a threshold of more than $3.4 \mathrm{~m} / \mathrm{s}$ for TRV would have been missed in $48 \%$ of patients [29]. The sensitivity of TDE at rest in our study was higher and this might be because the DETECT study presented a "real-world" echocardiographic assessment without clear pre-evaluation of investigators and training of this method. In contrast, in our study, TDE was more standardised. The results of our study suggest that accuracy of TDE could probably increase even more if further parameters such as RA and ventricular area were included. This was also recommended in the Delphi consensus study [30]. The current recommendation from the Scleroderma Foundation and Pulmonary Hypertension Association for screening of $\mathrm{PH}$ [31] is to use a combination of DLCO, TDE (both high evidence), NT-proBNP, and the DETECT algorithm if DLCO\% is less than $60 \%$ and disease duration is more than 3 years (both moderate evidence) [11].

\section{Role of stress Doppler echocardiography in the screening for pulmonary hypertension in patients with systemic sclerosis}

Within the last 10 years, SDE has been increasingly used to assess pulmonary circulation [15]. Alkotob et al. (2006) reported for the first time that a PASP increase more than $40 \mathrm{~mm} \mathrm{Hg}$ during exercise was associated with a higher risk of developing manifest PH [13]. Furthermore, patients with exercise-induced $\mathrm{PH}$ reached lower workloads [12] and exercise time [13]. Steen et al. (2008) identified 17 out of 21 patients with $\triangle$ PASP increase of more than $20 \mathrm{~mm} \mathrm{Hg}$ during exercise and suggested that these patients are at risk for $\mathrm{PH}$ [32]. All of these patients were symptomatic, but only $19 \%$ of patients had a manifest $\mathrm{PH}$ according to the current definition (mPAP of at least $25 \mathrm{~mm} \mathrm{Hg}$ ). Kovacs et al. (2010) showed a close correlation between pulmonary artery pressures (PAPs) obtained by SDE and RHC during exercise and confirmed less 6MWD in patients with SScAPAH [12]. Codullo et al. (2013) demonstrated, in a

Table 3 Comparison of screening algorithms for pulmonary hypertension in systemic sclerosis

\begin{tabular}{|c|c|c|c|c|c|}
\hline Approach & $\begin{array}{l}\text { False negatives, \% } \\
\text { (missed diagnoses) }\end{array}$ & Sensitivity, \% & Specificity, \% & PPV, \% & NPV, $\%$ \\
\hline SDE at rest and during exercise & 1 & 96 & 82 & 68 & 98 \\
\hline \multicolumn{6}{|l|}{$N=76$} \\
\hline DETECT algorithm & 4 & 96 & 48 & 35 & 98 \\
\hline \multicolumn{6}{|l|}{$N=319$} \\
\hline DETECT algorithm with & 15 & 85 & 72 & 47 & 94 \\
\hline \multicolumn{6}{|l|}{$65 \%$ specificity at step 2} \\
\hline \multicolumn{6}{|l|}{$N=319$} \\
\hline \multicolumn{6}{|l|}{ DETECT data with algorithm from } \\
\hline ESC/ERS guidelines* & 29 & 71 & 69 & 40 & 89 \\
\hline$N=371$ & & & & & \\
\hline
\end{tabular}

PPV positive predictive value (confirmed pulmonary arterial hypertension out of all right heart catheterization referrals), NPV negative predictive value, SDE stress Doppler echocardiography, ESC/ERS European Society of Cardiology/European Respiratory Society

Adaptation of the table provided by Coghlan et al. [11] in the DETECT study

*Evaluated on a subset of patients from DETECT study $(n=371)$ with available data for the variables defined in the guideline

Criteria were the following: (a) tricuspid regurgitant jet velocity $>3.4 \mathrm{~m} / \mathrm{s}$ or (b) tricuspid regurgitant jet velocity $>2.8$ to $\leq 3.4 \mathrm{~m} / \mathrm{s}$ AND symptomatic (defined as at least one of the following DETECT parameters: current anginal pain, current syncope/near syncope, current dyspnoea, or presence of peripheral oedema) or (c) tricuspid regurgitant jet velocity $\leq 2.8 \mathrm{~m} / \mathrm{s}$ AND symptomatic (defined as above) AND presence of additional echocardiography variables suggestive of pulmonary hypertension (defined as right atrium area $>16 \mathrm{~cm}^{2}$ or ratio of right ventricular diameter/left ventricular end diastolic diameter $>0.8$ or both) 
low-risk cohort of 170 patients, that increased $\triangle$ PASP during SDE is a risk factor for the development of manifest PH [33]. All of these studies showed certain aspects of SDE and identified elevated PASP during exercise as a risk factor for the development of pulmonary vascular disease. However, none of these studies assessed sensitivity and specificity of this method in identifying $\mathrm{PH}$ using RHC as the gold standard in all patients. Our results indicate that SDE can be a reliable non-invasive screening method for early manifest PAH in SSc if the assessment is standardised. There are the first data indicating that an early treatment with $\mathrm{PH}$-targeted therapy might attenuate PASP increase in patients with borderline $\mathrm{PH}$ in SSc [34]. However, the role of early treatment in SScAPAH is still to be investigated by randomised controlled trials.

\section{Which cutoff value for systolic pulmonary arterial pressures is useful?}

The current ESC/ERS guidelines did not recommend SDE [6] and this was due mainly to the lack of agreement on cutoff values for PASP during exercise. A PASP of $40 \mathrm{~mm} \mathrm{Hg}$ is usually taken as the upper limit of normal $[4,35-37]$, even though this value may be exceeded during exercise by athletes with a $\mathrm{CO}$ far above $10 \mathrm{l} / \mathrm{min}$ [38]. Therefore, assessment of exercise-induced increases in PAPs should be interpreted relative to increases in blood flow (i.e., $\triangle \mathrm{PASP} / \triangle \mathrm{CO}$ ) and specific work rates rather than relying on a single absolute PASP or mPAP threshold or a peak exercise PAP $[15,39,40]$. Therefore, in this study, we used PASPs of $40 \mathrm{~mm} \mathrm{Hg}$ at rest and of $45 \mathrm{~mm} \mathrm{Hg}$ during low-dose exercise (25 Watts) with COs clearly less than $10 \mathrm{l} / \mathrm{min}$ as cutoff values. This is in line with previous data in healthy subjects $[16,38]$ and methodological prediction formulas (Syyed and Chemla) of PAP [23-25].

\section{Limitations}

Results of SDE can be affected by concomitant diseases such as left heart disease or lung diseases. In our study, the presence of left ventricular dysfunction associated with high PAWP led to false-positive results in SDE [41, 42]. Therefore, in all patients with elevated PAP and high systemic blood pressures or pulmonary artery wedge pressures, a left heart catheterisation has been performed.

Furthermore, in any screening program, it cannot be excluded that there is a referral bias due to the fact that predominantly those patients are willing to perform the screening who already feel some symptoms. Nevertheless, we have included consecutive patients despite symptoms which resulted in a high proportion of patients $(22 \%)$ with no or only mild symptoms in our cohort.

TDE and SDE are somewhat dependent on experienced investigators and standardisation of the procedure.
Thus, these results may not present a non-standardised screening process. In general, standardisation might be necessary and useful when screening SSc patients for $\mathrm{PH}$. The underlying disease, especially in the case of $\mathrm{dcSSc}$ with interfering musculoskeletal involvement, may have influenced the results of the exercise test. The parameter of PASP during exercise in this study corresponds to a workload of 25 Watts. An impaired exercise capacity is therefore assumed to have no crucial impact on the results.

\section{Conclusions}

The results of this prospective cross-sectional study using RHC as gold standard in all patients showed that SDE markedly improved sensitivity in detecting manifest $\mathrm{PH}$ to $95.2 \%$ compared with $72.7 \%$ in echocardiography at rest in patients with SSc. Thus, for PH screening in patients with SSc, it might be useful to perform echocardiography at rest and during exercise.

\section{Abbreviations}

6MWD: 6-minute walking distance; APAH: Associated pulmonary arterial hypertension; Cl: Confidence interval; CO: Cardiac output; CT: Computed tomography; dcSSc: Diffuse cutaneous systemic sclerosis; DLCO: Diffusing capacity of the lung for carbon monoxide; ERS: European Respiratory Society; ESC: European Society of Cardiology; FC: Functional class; FVC: Forced vital capacity; HFpEF: Heart failure with preserved ejection fraction; IcSSc: Limited cutaneous systemic sclerosis; MPAP: Mean pulmonary arterial pressure; NT-proBNP: N-type bro brain natriuretic peptide; PAH: Pulmonary arterial hypertension; PAP: Pulmonary artery pressure; PASP: Systolic pulmonary arterial pressure; PAWP: Pulmonary arterial wedge pressure; PH: Pulmonary hypertension; RA: Right atrial; RHC: Right heart catheterisation; ROC: Receiver operating characteristic; RV: Right ventricular; SDE: Stress Doppler echocardiography; SPAP: Systolic pulmonary arterial pressure; SSc: Systemic sclerosis; SSC-APAH: Systemic sclerosis associated pulmonary arterial hypertension; TDE: Transthoracic Doppler echocardiography; TRV: Tricuspid regurgitation velocity; WHO: World Health Organization.

\section{Competing interests}

The authors declare that they have no competing interests.

\section{Authors' contributions}

$\mathrm{CN}, \mathrm{EG}, \mathrm{BE}$ and $\mathrm{PH}$ helped to acquire the data and to perform the interpretation of data. NE and CFis performed the statistical analysis and helped to perform the interpretation of data. $A D, N B, E B, A B, C F i e, H-M L$, and FS helped to perform the interpretation of data. All authors have made substantial contributions to conception and design, have been involved in drafting the manuscript and revised it critically for important intellectual content, have given final approval of the version to be published, and agree to be accountable for all aspects of the work in ensuring that questions related to the accuracy or integrity of any part of the work are appropriately investigated and resolved.

\section{Acknowledgements}

We would like to thank all patients who participated in the study.

\section{Author details}

${ }^{1}$ Centre for Pulmonary Hypertension Thoraxclinic, University Hospital Heidelberg, Amalienstr. 5, 69126 Heidelberg, Germany. 'Lung Centre, Klinikum Mittelbaden, Balger Str. 50, 76532 Baden-Baden Balg, Germany.

${ }^{3}$ Department of Cardiothoracic Sciences, Monaldi Hospital, Second University of Naples, Via Leonardo Bianchi, 1, 80131 Naples, Italy. ${ }^{4}$ Division of Rheumatology, University Hospital Heidelberg, Im Neuenheimer Feld 410, 69120 Heidelberg, Germany. 'Department of Cardiology and Cardiac Surgery, University Hospital "Scuola Medica Salernitana", Via Pr. Amedeo, 36-83023 
Lauro (AV) Salerno, Italy. ${ }^{6}$ Rheumapraxis Landau, Industriestraße 9, 76829 Landau in der Pfalz, Germany. ${ }^{7}$ Department of Rheumatology, ACURA-Klinik Baden-Baden, Rotenbachtalstr. 5, 76530 Baden-Baden, Germany. ${ }^{8}$ Department of Human Genetics, University of Heidelberg, Im Neuenheimer Feld 366 69120 Heidelberg, Germany. ${ }^{9}$ Klinikum Darmstadt, Medizinische Klinik III, Grafenstraße 9, 64283 Darmstadt, Germany.

\section{Received: 11 March 2015 Accepted: 2 June 2015} Published online: 19 June 2015

\section{References}

1. Mukerjee D, St George D, Coleiro B, Knight C, Denton CP, Davar J, et al. Prevalence and outcome in systemic sclerosis associated pulmonary arterial hypertension: application of a registry approach. Ann Rheum Dis. 2003:62:1088-93.

2. Wigley FM, Lima JA, Mayes M, McLain D, Chapin JL, Ward-Able C. The prevalence of undiagnosed pulmonary arterial hypertension in subjects with connective tissue disease at the secondary health care level of communitybased rheumatologists (the UNCOVER study). Arthritis Rheum. 2005:52:2125-32 doi:10.1002/art21131.

3. Hachulla E, Carpentier P, Gressin V, Diot E, Allanore Y, Sibilia J, et al. Risk factors for death and the 3-year survival of patients with systemic sclerosis: the French ItinerAIR-Sclerodermie study. Rheumatology (Oxford, England). 2009:48:304-8. doi:10.1093/rheumatology/ken488.

4. Hachulla E, Gressin V, Guillevin L, Carpentier P, Diot E, Sibilia J, et al. Early detection of pulmonary arterial hypertension in systemic sclerosis: a French nationwide prospective multicenter study. Arthritis Rheum. 2005;52:3792-800. doi:10.1002/art.21433.

5. Galie N, Corris PA, Frost A, Girgis RE, Granton J, Jing ZC, et al. Updated treatment algorithm of pulmonary arterial hypertension. J Am Coll Cardiol. 2013;62:D60-72. doi:10.1016/j.jacc.2013.10.031.

6. Galie N, Hoeper MM, Humbert M, Torbicki A, Vachiery JL, Barbera JA, et al. Guidelines for the diagnosis and treatment of pulmonary hypertension. The task force for the diagnosis and treatment of pulmonary hypertension of the European Society of Cardiology (ESC) and the European Respiratory Society (ERS), endorsed by the International Society of Heart and Lung Transplantation (ISHLT). Eur Respir J. 2009:34:1219-63. doi:10.1183/09031936.00139009.

7. Grunig E, Barner A, Bell M, Claussen M, Dandel M, Dumitrescu D, et al. Non-invasive diagnosis of pulmonary hypertension: ESC/ERS Guidelines with Updated Commentary of the Cologne Consensus Conference 2011. Int J Cardiol. 2011;154 Suppl 1:S3-12. doi:10.1016/s0167-5273(11)70488-0.

8. Olschewski H, Hoeper MM, Borst MM, Ewert R, Grunig E, Kleber FX, et al. Diagnosis and therapy of chronic pulmonary hypertension. Pneumologie (Stuttgart, Germany). 2006:60:749-71. doi:10.1055/s-2006-954981.

9. Mukerjee D, St George D, Knight C, Davar J, Wells AU, Du Bois RM, et al. Echocardiography and pulmonary function as screening tests for pulmonary arterial hypertension in systemic sclerosis. Rheumatology (Oxford, England). 2004:43:461-6. doi:10.1093/rheumatology/keh067.

10. Launay D, Mouthon L, Hachulla E, Pagnoux C, de Groote P, Remy-Jardin M, et al. Prevalence and characteristics of moderate to severe pulmonary hypertension in systemic sclerosis with and without interstitial lung disease. J Rheumatol. 2007;34:1005-11.

11. Coghlan JG, Denton CP, Grunig E, Bonderman D, Distler O, Khanna D, et al Evidence-based detection of pulmonary arterial hypertension in systemic sclerosis: the DETECT study. Ann Rheum Dis. 2014;73:1340-9. doi:10.1136/annrheumdis-2013-203301.

12. Kovacs G, Maier R, Aberer E, Brodmann M, Scheidl S, Hesse C, et al. Assessment of pulmonary arterial pressure during exercise in collagen vascular disease: echocardiography vs right-sided heart catheterization. Chest. 2010;138:270-8. doi:10.1378/chest.09-2099.

13. Alkotob ML, Soltani P, Sheatt MA, Katsetos MC, Rothfield N, Hager WD, et al. Reduced exercise capacity and stress-induced pulmonary hypertension in patients with scleroderma. Chest. 2006;130:176-81. doi:10.1378/ chest.130.1.176.

14. Condliffe R, Kiely DG, Peacock AJ, Corris PA, Gibbs JS, Vrapi F, et al. Connective tissue disease-associated pulmonary arterial hypertension in the modern treatment era. Am J Respir Crit Care Med. 2009;179:151-7. doi:10.1164/rccm.200806-953OC.

15. Lewis GD, Bossone E, Naeije R, Grunig E, Saggar R, Lancellotti P, et al. Pulmonary vascular hemodynamic response to exercise in cardiopulmonary diseases. Circulation. 2013;128:1470-9. doi:10.1161/circulationaha.112.000667.
16. Grunig E, Weissmann S, Ehlken N, Fijalkowska A, Fischer C, Fourme T, et al. Stress Doppler echocardiography in relatives of patients with idiopathic and familial pulmonary arterial hypertension: results of a multicenter European analysis of pulmonary artery pressure response to exercise and hypoxia. Circulation. 2009;119:1747-57. doi:10.1161/circulationaha.108.800938.

17. Preliminary criteria for the classification of systemic sclerosis (scleroderma). Subcommittee for scleroderma criteria of the American Rheumatism Association Diagnostic and Therapeutic Criteria Committee. Arthritis Rheum. 1980;23:581-90.

18. ATS Committee on Proficiency Standards for Clinical Pulmonary Function Laboratories. ATS statement: guidelines for the six-minute walk test. Am J Respir Crit Care Med. 2002;166:111-7. doi:10.1164/ajrccm.166.1.at1102.

19. Yock PG, Popp RL. Noninvasive estimation of right ventricular systolic pressure by Doppler ultrasound in patients with tricuspid regurgitation. Circulation. 1984;70:657-62.

20. Ommen SR, Nishimura RA, Appleton CP, Miller FA, Oh JK, Redfield MM, et al. Clinical utility of Doppler echocardiography and tissue Doppler imaging in the estimation of left ventricular filling pressures: a comparative simultaneous Doppler-catheterization study. Circulation. 2000;102:1788-94.

21. Jae E. The Clinical Aspects of Venous Pressure. New York: Macmillan; 1929.

22. Argiento $\mathrm{P}$, Chesler N, Mule M, D'Alto M, Bossone E, Unger P, et al. Exercise stress echocardiography for the study of the pulmonary circulation. Eur Respir J. 2010;35:1273-8. doi:10.1183/09031936.00076009.

23. Chemla D, Castelain V, Humbert M, Hebert JL, Simonneau G, Lecarpentier $Y$, et al. New formula for predicting mean pulmonary artery pressure using systolic pulmonary artery pressure. Chest. 2004;126:1313-7. doi:10.1378/ chest.126.4.1313.

24. Syyed R, Reeves JT, Welsh D, Raeside D, Johnson MK, Peacock AJ. The relationship between the components of pulmonary artery pressure remains constant under all conditions in both health and disease. Chest. 2008;133:633-9. doi:10.1378/chest.07-1367.

25. Aduen JF, Castello R, Daniels JT, Diaz JA, Safford RE, Heckman MG, et al. Accuracy and precision of three echocardiographic methods for estimating mean pulmonary artery pressure. Chest. 2011;139:347-52. doi:10.1378/ chest.10-0126.

26. Murata I, Kihara H, Shinohara S, Ito K. Echocardiographic evaluation of pulmonary arterial hypertension in patients with progressive systemic sclerosis and related syndromes. Jpn Circ J. 1992;56:983-91.

27. Denton CP, Cailes JB, Phillips GD, Wells AU, Black CM, Bois RM. Comparison of Doppler echocardiography and right heart catheterization to assess pulmonary hypertension in systemic sclerosis. Br J Rheumatol. 1997;36:239-43.

28. Hsu VM, Moreyra AE, Wilson AC, Shinnar M, Shindler DM, Wilson JE, et al. Assessment of pulmonary arterial hypertension in patients with systemic sclerosis: comparison of noninvasive tests with results of right-heart catheterization. J Rheumatol. 2008:35:458-65.

29. Hao Y, Thakkar V, Stevens W, Morrisroe K, Prior D, Rabusa C, et al. A comparison of the predictive accuracy of three screening models for pulmonary arterial hypertension in systemic sclerosis. Arthritis Res Ther. 2015;17:7. doi:10.1186/s13075-015-0517-5.

30. Avouac J, Huscher D, Furst DE, Opitz CF, Distler O, Allanore Y. Expert consensus for performing right heart catheterisation for suspected pulmonary arterial hypertension in systemic sclerosis: a Delphi consensus study with cluster analysis. Ann Rheum Dis. 2014;73:191-7. doi:10.1136/ annrheumdis-2012-202567.

31. Khanna D, Gladue H, Channick R, Chung L, Distler O, Furst DE, et al. Recommendations for screening and detection of connective tissue disease-associated pulmonary arterial hypertension. Arthritis Rheum. 2013;65:3194-201. doi:10.1002/art.38172

32. Steen V, Chou M, Shanmugam V, Mathias M, Kuru T, Morrissey R. Exerciseinduced pulmonary arterial hypertension in patients with systemic sclerosis. Chest. 2008;134:146-51. doi:10.1378/chest.07-2324.

33. Codullo V, Caporali R, Cuomo G, Ghio S, D'Alto M, Fusetti C, et al. Stress Doppler echocardiography in systemic sclerosis: evidence for a role in the prediction of pulmonary hypertension. Arthritis Rheum. 2013;65:2403-11. doi:10.1002/art.38043.

34. Kovacs G, Maier R, Aberer E, Brodmann M, Graninger W, Kqiku X, et al. Pulmonary arterial hypertension therapy may be safe and effective in patients with systemic sclerosis and borderline pulmonary artery pressure. Arthritis Rheum. 2012:64:1257-62. doi:10.1002/art.33460.

35. McLaughlin W, Archer SL, Badesch DB, Barst RJ, Farber HW, Lindner JR, et al. ACCF/AHA 2009 expert consensus document on pulmonary hypertension a 
report of the American College of Cardiology Foundation Task Force on Expert Consensus Documents and the American Heart Association developed in collaboration with the American College of Chest Physicians; American Thoracic Society, Inc;; and the Pulmonary Hypertension Association. J Am Coll Cardiol. 2009;53:1573-619. doi:10.1016/j.jacc.2009.01.004.

36. Galie N, Torbicki A, Barst R, Dartevelle P, Haworth S, Higenbottam T, et al. Guidelines on diagnosis and treatment of pulmonary arterial hypertension. The Task Force on Diagnosis and Treatment of Pulmonary Arterial Hypertension of the European Society of Cardiology. Eur Heart J. 2004;25:2243-78. doi:10.1016/j.ehj.2004.09.014.

37. Grunig E, Janssen B, Mereles D, Barth U, Borst MM, Vogt IR, et al. Abnormal pulmonary artery pressure response in asymptomatic carriers of primary pulmonary hypertension gene. Circulation. 2000;102:1145-50.

38. Bossone E, Rubenfire M, Bach DS, Ricciardi M, Armstrong WF. Range of tricuspid regurgitation velocity at rest and during exercise in normal adult men: implications for the diagnosis of pulmonary hypertension. J Am Coll Cardiol. 1999:33:1662-6.

39. Argiento P, Vanderpool RR, Mule M, Russo MG, D'Alto M, Bossone E, et al. Exercise stress echocardiography of the pulmonary circulation: limits of normal and sex differences. Chest. 2012;142:1158-65. do:10.1378/chest.12-0071.

40. Naeije R, Vanderpool R, Dhakal BP, Saggar R, Saggar R, Vachiery JL, et al. Exercise-induced pulmonary hypertension: physiological basis and methodological concerns. Am J Respir Crit Care Med. 2013;187:576-83. doi:10.1164/rccm.201211-2090Cl.

41. Voilliot D, Magne J, Dulgheru R, Kou S, Henri C, Laaraibi S, et al. Determinants of exercise-induced pulmonary arterial hypertension in systemic sclerosis. Int Cardiol. 2014;173:373-9. doi:10.1016/j.jcard.2014.02.042.

42. Gargani L, Pignone A, Agoston G, Moreo A, Capati E, Badano LP, et al. Clinical and echocardiographic correlations of exercise-induced pulmonary hypertension in systemic sclerosis: a multicenter study. Am Heart J. 2013;165:200-7. doi:10.1016/j.ahj.2012.10.020

\section{Submit your next manuscript to BioMed Central and take full advantage of:}

- Convenient online submission

- Thorough peer review

- No space constraints or color figure charges

- Immediate publication on acceptance

- Inclusion in PubMed, CAS, Scopus and Google Scholar

- Research which is freely available for redistribution 